Journal of Engineering and Applied Sciences 14 (Special Issue 7): 10058-10066, 2019

ISSN: 1816-949X

(C) Medwell Journals, 2019

\title{
Methods in Single Phase to Ground Faults on Power Distribution Systems
}

\author{
${ }^{1}$ Dur Muhammad Soomro, ${ }^{2}$ Adnan Hasan Tawafan and ${ }^{3}$ Feryal Ibrahim Jabbar \\ ${ }^{1}$ Faculty of Electrical and Electronic Engineering, Universiti Tun Hussein Onn Malaysia, \\ Parit Raja, Malaysia \\ ${ }^{2}$ Karbala Technical Institute, \\ ${ }^{3}$ Babylon Technical Institute, Al-Furat Al-Awsat Technical University, Kufa, Iraq
}

\begin{abstract}
This study highlights the main contributions for the single phase to ground faults on distribution networks field throughout a last three decades from classic methods to heuristic methods. The surveys about 76 papers that are published in the field, the quantity of existing methods for each method is determined and categorized. The study includes graphs and tables explaining the frequency of each single phase to ground faults methods and so that, researchers in the same field can be used this paper as a guideline for their research.
\end{abstract}

Key words: Single phase to ground faults, distribution power network, detection fault, classic, heuristic, guideline

\section{INTRODUCTION}

Fault detection on power distribution networks represents a high important matter to consider to ensure reliability, safety and to prevent accidents, failure in equipment and undesired outage. The source of fault may be caused result from different reasons such like contact between lines through metal that produces a short circuit path, contact due to trees and wind or temporary contact of birds or animals. Number of faults lasts for a short duration of time and get back to healthy operating state, this type of faults are called temporary faults. Other form of faults is called permanent faults which will stay till the short circuit is recognized and cleared. If temporary fault is not removed, finally it will become permanent fault sooner or later. Permanent faults may be caused due to different reasons such as metal objects falling on overhead lines, failure of cable insulation due to incorrect maintenance and lines falling on Earth. In distribution systems, faults can classify into four main types; single line to ground fault, line to line fault, double line to ground fault and three-phase to ground fault. Single line to ground fault SLGF happens when one conductor of a distribution network has touched earth through animal contact or a line fall on the earth. The $70 \%$ of fault in distribution systems is due to single line to ground fault (Lim and Dorr, 2000). Line to Line Faults LLF happens when one of three phase touch another phase due to high wind while $15 \%$ of fault in distribution systems is a type of line to line fault (Lim and Dorr, 2000). Double Line to Ground Fault DLGF happens at the rate of $10 \%$ in distribution network (Lim and Dorr, 2000). Three-Phase to Ground Fault TPGF may be produced due to failure in equipment, a conductor makes contact with other phases or tower falling on ground. Generally, TPGF is not common at the rate of $5 \%$ in distribution network (Lim and Dorr, 2000). Although, the fault is not frequent, the happening of TPGF is risky when fault current is very large. Hence, with a view to prevent equipment damage and customer loss, fault has to be cleared as soon as possible. According to a study by Piesciorovsky and Schulz (2017), faults are the reason for more than $80 \%$ of the interruptions in distribution network. Generally, the SLGF represents the most common one and want to detect, so that, the faulty feeder can be isolated and want to detect, so that, the faulty feeder can be isolated quickly (Lim and Dorr, 2000).

Use overcurrent devices for detecting faults in distribution network are the most common practice of utilities. Overcurrent devices track the current in line and detect a fault when the current become higher than a threshold of overcurrent devices (Piesciorovsky and Schulz, 2017; Nikolaidis et al., 2016). The threshold for overcurrent devices depend on the load current. Commonly, the value of threshold is a slightly higher than the rated load current of the feeder. However, this technique does not detect the fault that draws current less than threshold level during fault occurrence. Furthermore, the amount of fault current during ground faults occurrence in a power distribution network depends on the type of grounding of distribution substation transformer where fault current is desired to be very low for healthy feeder. There are various way for grounding of substation transformer, e.g., ungrounded system, solidly grounded system, resistance grounded system and Resonant Grounding system (RG). Among these types of

Corresponding Author: Dur Muhammad Soomro, Faculty of Electrical and Electronic Engineering, Universiti Tun Hussein Onn Malaysia, Parit Raja, Malaysia 
grounding, resonant grounding system based techniques can reduce the fault current of SLGF to a very small value depending on line impedance and impedance of fault. This means that the value of fault currents is very small and the overcurrent devices do not detect.

\section{MATERIALS AND METHODS}

\section{Nature of single phase to ground faults and simulation and general consideration}

Nature: Distribution system protection plays an important role in the security and reliability of power supply to customers by isolating an affected section of the system when a fault occurs. Many medium voltage distribution networks around the world are neutral through Resonant Grounding system (RG) (Lim and Dorr, 2000). The advantage of resonant grounding system just produces small zero sequence current in the system and the current flows through line to ground capacitance, moreover, the voltage between lines remains symmetrical and does not have effect on the load of power supply. Hence, fault detection in Resonant Grounding system (RG) is a significant problem in that there is a large amount of fuzziness in the fault information for fault diagnosis. This situation is mainly attributed to the following factors: faults usually do not draw enough fault current to operate conventional protective devices due to lower voltage levels and higher system impedances (Zeng et al., 2008; Cui et al., 2010). Operating condition variations invalidate the protection schemes that have predetermined setting value. Different fault cases exhibit complex sets of features and widely varying behaviors which limit the application of protection schemes based on single fault features (Lin et al., 2010).

Simulation: Most of researchers have used special software program for model the single line to ground fault on power distribution network, researchers use signals that get from simulation to collect data about the feeder at healthy and unhealthy operation then signals are examined by using certain methods to detect faults.

There are several types of software program used for simulation power distribution systems, some of researchers have used Electromagnetic Transients Program (EMTP) for illustrating their system (Wang et al., 2016; Heidari, 2010; Hanninen, 2001; Zhang et al., 2011; Sheng and Rovnyak, 2004; Wai and Yibin, 1998; Eldin et al., 2009; Chang, 2010; Lobos et al., 2001; Yeo et al., 2003; Chaari and Meunier, 1994; Ravlic and Marusic, 2015; Perera et al., 2009; Wang et al., 2013; Mora et al., 2006; Kasinathan, 2007; Robertson et al., 1996; Loos et al., 2013; Guo and Yang, 2017; Loos, 2013; Elkalashy et al., 2007; Yan-wen et al., 2011; Dwivedi and Yu, 2011; Vijayachandran and Mathew, 2012; Dong and Shi, 2008; Lin et al., 2011;
Nayebi et al., 2012; Kawady et al., 2010; Michalik et al., 2007; Bi et al., 2004; Lai et al., 2012; Sedighi et al., 2005; Chaari et al., 1996; Lin et al., 2014; Zeng et al., 2008; Kim et al., 2004; Assef et al., 1998. Others have used the Power Systems Computer Aided Design (PSCAD) for implementing power system (Hietalahti, 2010; Zeng et al., 2017; Chen et al., 2015; Jansson and Wadstrom, 2014; Venkataraman et al., 2014; Zhou et al., 2017; Wang et al., 2015; Shao et al., 2016; Barik et al., 2018), simulations are conducted in MATLAB/SimPower systems to get the fault signals (Venkataraman et al., 2014; Zhou et al., 2017; Wang et al., 2015; Shao et al., 2016; Barik et al., 2018; Sagastabeitia et al., 2011).

Simulation includes extensive scenarios for various operation mode of distribution network. The simulation scenarios are as follows:

- Changing the reactance of the arc suppression coil for getting various compensated ratio to simulate different compensation scenarios

- Varying the factors of distribution lines, involved the conductance and lengths of the lines for simulating various practical conditions in distribution network

- Change the inception angle of the fault

- Change the resistance of neutral for testing immune of method to high transition resistance

Adaptive arc suppression coil grounded network: When a single line ground faults occur in a distribution network, arc suppression coil is designed to be in a entire parallel resonance to the ground capacitance, thus, for entire compensating the fault point current and effective way for preventing firing an arc at the fault point and extinguish the arc in shortly duration.

Arc suppression coil is set to be over-compensating with the ground capacitance. If arc suppression coil sets entire compensating the ground capacitance of the network or nearly resonance, that may create series resonance and produce hazardous overvoltage, if the voltages between lines are little non-symmetrical and a zero sequence voltage creates during normal operation case (Xiaobin et al., 2018).

In the following sections, various approaches to detect single phase to ground fault are reviewed and in the conclusions, these algorithms are compared. The taxonomy of these algorithms is shown in Fig. 1. This figure declares that detection methods of SLGF either depend on based on intelligently decisive tools or classically extracting the features.

SLGF features used in detection methods: There were methods presented based on the displacement of neutral voltage (Sagastabeitia et al., 2011) where an increase the neutral voltage due to unbalance between phase voltages. Moldovanova et al. (2016) proposed method based on 


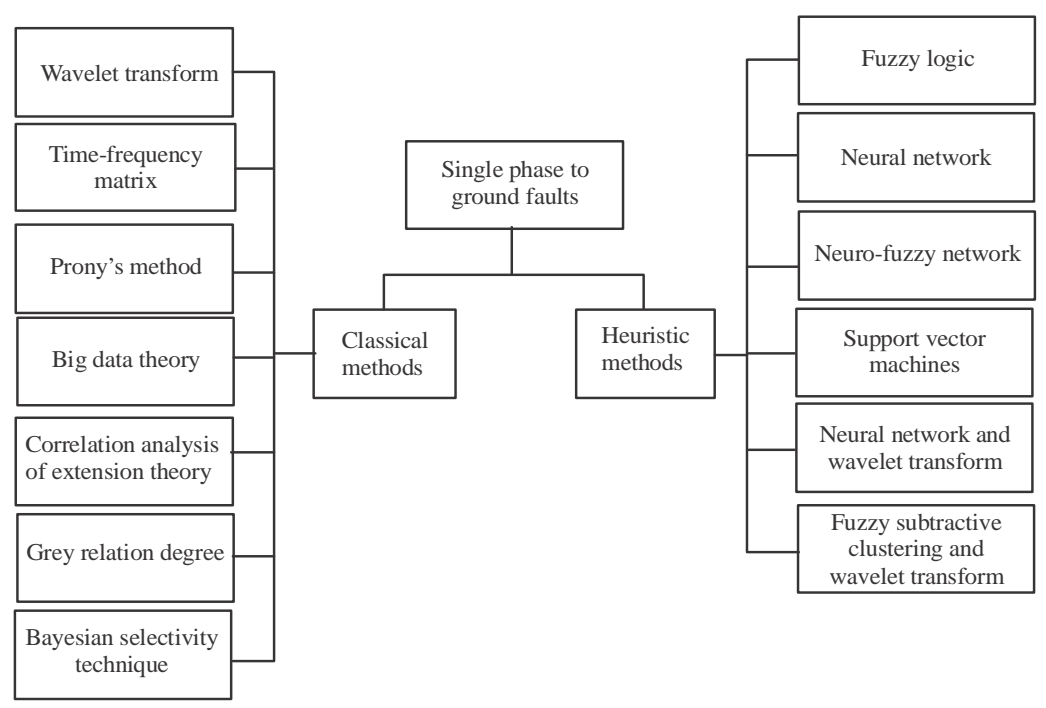

Fig. 1: Taxonomy of single phase to ground fault detection algorithms detect

characteristics of steady-state current when SLGF occurs, only the steady-state current of the fault phase load superimposed on the fault feeder upstream to the substation switch will change while the steady-state current of the other paths will not change. Therefore, the method of fault detection is to find the path for power supply from the substation switch to the fault point.

Algorithms based on transient zero-sequence: $\mathrm{Bi}$ et al. (2004) presents a novel method for selection fault feeder based on the transient signal and wavelet transform. It captures zero-sequence current of the post-fault transient of each feeder and wavelet transform is utilized for extracting the high frequency components and supply fundamental frequency. Guo and Yang (2017) analyzes the amplitude-frequency spectra of zero-sequence current in the network with neutral grounding through Peterson-coil under transient earth faults. A detection algorithm utilize the value of the zero-sequence current of the unhealthy feeder must be higher than that of any other healthy feeder for detection single phase to ground fault (Lin et al., 2011). Dong and Shi (2008) utilizes zero-sequence current traveling waves for identifying the faulty feeder and the residual voltage of bus bar for determining a status due to fault or switch operation. Liu and Huang (2017), a novel method to detect fault feeder is suggested, based on a Polarity Distribution Matrix (PDM) and Time-Frequency Matrix (TFM) singular values clustering algorithm. By using waveform transformation and a Hilbert-Huang transform band-pass filter to the waveform of transient zerosequence current for each feeder. Chaari and Meunier (1994) has used a recursive wavelet transform to analyze two types of currents during the fault: the zero-sequence current in the faulted feeder and also the zero-sequence current in the healthy feeder. Longhua and Qinghai (2002) presents algorithm including two units: a fault feeder identification unit and a fault event detection unit. the algorithm is based on data distribution kurtosis of transient zero-sequence current, both units are sued for detection whether a SLGF has occurred and capture the time of starting fault. Bin and Hongchun (2008) uses principle that is based on the feature that the amplitude of zero-sequence current of faulty feeder is higher than that of sound feeder, therefore, the selective ground-fault protection can be detected simply. By Li (2013), the characteristics variables of zero-sequence current and the correlation function are utilized for identifying the correlation then the results use for selection the faulted feeder. Ma et al. (2015) wavelet signals of the zero-sequence current are separated and extracted that is based on the method of discrete wavelet multi resolution analysis. Lin et al. (2010) the compensation method is presented to review the zero-sequence admittances difference between the faulty line and healthy line.

Algorithms based on voltage phase comparison: Chunju et al. (2007) has used the phase relationship between the negative sequence current at the fault point and the negative sequence current at substation to calculate angular difference between the fault voltage and the measured current.

SLGF feature extractors: SLGs are followed by variations in the fundamental frequency and harmonic components. However, these variations are dynamics that have caused time varying in nature due to the dynamics of arc faults. Consequently, methods that explain how can 


\section{J. Eng. Applied Sci., 14 (Special Issue 7): 10058-10066, 2019}

use the time varying nature of the fundamental and harmonic components using signal processing methods such as Porny method, wavelet transform and grey relation degree and other techniques to recognize the pattern of fault current signals are convenience to identify the SLGF. These algorithms are classified as follows:

Algorithms based on wavelet transform: By Dong and Shi (2008), a scheme of SLGF feeder identification in distribution system with the application of a wavelet transform technique is introduced. Bi et al. (2004) uses wavelet packet for extracting the supply fundamental frequency end high frequency components from the post-fault transient zero-sequence current of each feeder. Liang et al. (2002) wavelet transform is applied for extraction fault features from the fault currents. Neural network and fuzzy theory are used for fuzzifying the extracted features. The researcher creates wavelet fuzzy neural network by integrated the wavelet with fuzzy neural network. Chaari and Meunier (1994), a recursive wavelet transform is used for analyzing two types of fault currents that are the zero-sequence currents in the faulted feeder and in the sound feeder. Wangyi et al. (2009), the early detection theory based on the WT is utilized for processing fault current waveforms and an early detection method of SLGF is introduced for $10-\mathrm{kV}$ middle-voltage distribution networks. Zeng et al. (2017) the characteristics of SLGF transient signal is analyzed determinedly using wavelet transform. Chaari et al. (1996) wavelets are applied for analyzing transient SLGF in a $20 \mathrm{kV}$ resonant grounded network as generated by EMTP. Ma et al. (2016) wavelet signals of the zero-sequence current are separated and extracted that is based on the method of discrete wavelet multi resolution analysis.

Algorithms based on the grey relation degree: Wang et al. (2017) proposed a protection method to detect faulted feeder based on the grey relation degree for characterizing the similarity among waveforms signals. Slope relation degree, one kind of grey relation degrees is selected for characterizing the similarity between curves of transient zero-sequence currents for faulted feeder and other feeders and the slope relation matrix which represents the relationship among all feeders can be established.

Algorithms based on a time-frequency matrix: Liu and Huang (2018) presents a new fault detection scheme based on a Polarity Distribution Matrix (PDM) and Time-Frequency Matrix (TFM) singular values clustering algorithm. By using a waveform transformation and Hilbert-Huang transform band-pass filter for the transient zero-sequence current signals of each feeder. Chaari et al. (1995), the time-frequency matric is obtained by using the DWPT to the collected transient zero-sequence current signals of the faulted feeder and healthy feeders.

Algorithms based on Prony's method: This algorithm is used for analyzing earth fault currents in $20 \mathrm{kV}$ networks protected by arc suppression coil. The differences of Prony's parameters in terms of some of the power system features (capacitive current, fault resistance and distance between the busbar and the fault of the entire network) are presented (Elkalashy et al., 2010).

Algorithms based on theory of Big Data: Barik et al. (2018) uses big data theory for detecting faulty feeders by making use of a mass of data from the grid which contains of both electrical and non-electrical quantities.

Algorithms based extension theory: By Li (2013), the features of zero-sequence current and the correlation function are used for identifying correlation analysis and the matter element of extension theory and use the results to select the faulty lines.

Algorithms based on the Bayesian selectivity technique: Guo and Tian proposes technique mainly depends on using the Bayesian theorem after discrete wavelet transform-based transient feature extraction. By Fan (2017), a novel algorithm of fault line detection based on Bayesian compressed sensing theory was presented.

\section{Heuristic methods}

The fuzzy logic: By Liu and Huang (2018), fuzzy cmeans clustering is presented to the APFM for detection the fault feeder by classifying the faulty feeder and sound feeders into two categories without a certain threshold setting. By Zeng et al. (2016), a new SLGF protection method without threshold setting is presented. The fault detection is achieved based on operating states rather than setting values. A fuzzy c-means clustering is applied by classifying the operating state of the protected feeder into non-fault states and fault states.

Neural network: Momoh et al. (1997), the neural network method is used to design the single-phase earth fault detection model of distribution network. Bin Sulaiman et al. (2013), introduced an integrated package for fault detection in both grounded or ungrounded distribution network. It uses Artificial Neural Networks (ANN) for detection, classifying and locating 
faults. Assef et al. (1998) introduces algorithm based on making the comparison between the residual current and phase currents uses artificial neural networks.

The neuro-fuzzy network: Liang et al. (2002), wavelet transform is applied for extraction fault features from the fault currents. Neural network and fuzzy theory are used for fuzzifying the extracted features. The researcher creates wavelet fuzzy neural network by integrated the wavelet with fuzzy neural network.

Support vector machines: Yan-wen et al. (2011), Support Vector Machines (SVM) are utilized for recognizing the working situation of Peterson-coilgrounding system and for detection the fault feeder orbbus. Chaari et al. (1995), The two classifiers (Adaboost+CART and Support Vector Machines SVM) are presented. The classifiers are trained using a large number of characteristics vectors under different types of fault statuses and factors, respectively.

Combination of neural network and wavelet transform: DWT is used for extracting features of the high impedance fault and normal operation waveforms. The features extracted which includes the energy of approximate and detail coefficients of the current, voltage and power waveforms calculated at a selected level frequency are using for training and testing the Probabilistic Neural Network (PNN) for a precise classification of high impedance fault from normal operation.

\section{RESULTS AND DISCUSSION}

Chronological analysis: A total of 76 papers are surveyed in this study, covering a sufficient depth of works in the single phase to ground faults detection field for the last three decades. Most of the reviewed papers deal with determination of nature and behavior of single phase to ground faults as well as the presentation of type of program for simulation of these types of faults and general considerations about single phase to ground faults. These papers were explained in Section II. Researcher present their efforts about single phase to ground faults events detection which are presented in Fig. 1 in about $8 \%$ of papers. These papers were described in section $\mathrm{V}$. To simplify the analyzing process, abbreviations are used for the name of each method. These abbreviations are summarized in Table 1. According to this survey from the start of single phase to ground faults detection, about $60 \%$ of papers are related to classic algorithms and $40 \%$ to heuristic algorithms. This meaningful raising
Table 1: Abbreviations defined for various algorithms

\begin{tabular}{ll}
\hline Methods/Algorithm & ABB \\
\hline Classic methods & \\
Wavelet Transform & WT \\
Time Frequency Matrix & TFM \\
Prony's Method & PM \\
Big Data Theory & BDT \\
Correlation Analysis of Extension Theory & CAET \\
Grey Relation Degree & GRD \\
Bayesian Selectivity Technique & BST \\
Heuristic methods & \\
Fuzzy Logic & FL \\
Neural Network & NN \\
Neuro Fuzzy Network & NFN \\
Support Vector Machines & SVM \\
Neural Network and Wavelet Transform & NNWT \\
\hline
\end{tabular}

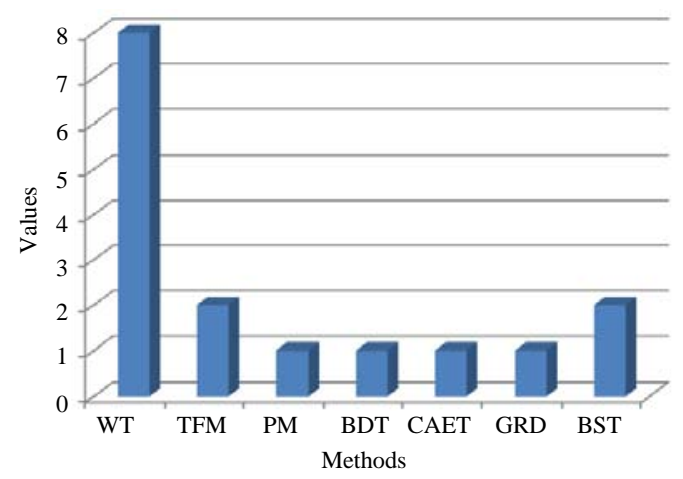

Fig. 2: No. of paper per classic methods

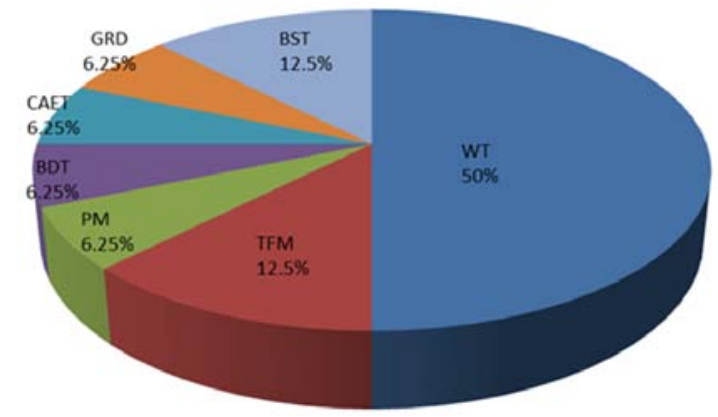

Fig. 3: The portion of contribution of each classic algorithm

in using the heuristic method is originated from the emergence of SPG detection based on neural networks.

The summary of above mentioned analysis is shown in Fig. 1. The portion of contribution for both classic and heuristic algorithms are shown in Fig. 2-5, respectively. Figure 2 and 4 show number of papers for both classic and heuristic algorithms and acronyms should be defined the first time they appear in the text, even after the have already been defined in the abstract. Do not use abbreviations in the title unless they are unavoidable. 


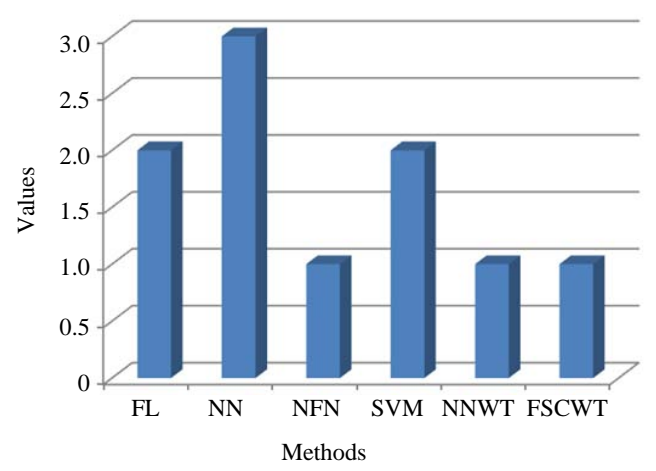

Fig. 4: No. of paper per heuristic methods

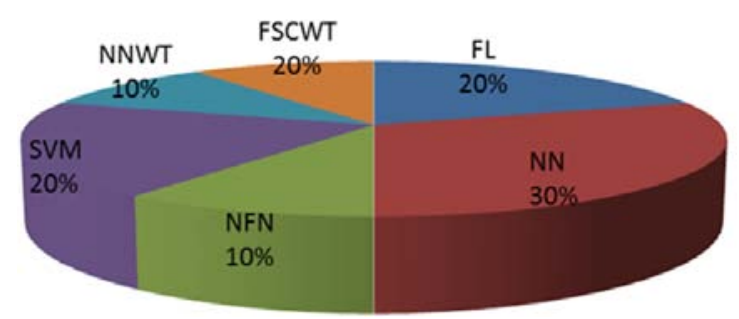

Fig. 5: The portion of contribution of each heuristic algorithm

\section{CONCLUSION}

In this study, near to 76 papers are surveyed about single phase to ground faults detection. This study classifies the mentioned algorithms to two major groups: classic methods and heuristic methods. Next, the algorithms belonging to each method are introduced. It terminates with tables and graphs determining the frequency of each algorithm. This study can be utilized as a guideline for researchers in this field where the single phase to ground faults detection is still a bending research area.

\section{REFERENCES}

Assef, Y., P. Bastard and M. Meunier, 1998. Artificial neural networks for single phase fault detection in resonant grounded power distribution systems. Proceedings of the 1996 IEEE International Conference on Transmission and Distribution Exposition, September 15-20, 1996, IEEE, Los Angeles, California, USA., pp: 566-572.

Barik, M.A., A. Gargoom, M.A. Mahmud, M.E. Haque and H. Al-Khalidi et al., 2018. A decentralized fault detection technique for detecting single phase to ground faults in power distribution systems with resonant grounding. IEEE. Trans. Power Delivery, 33: 2462-2473.
Bi, Y., J. Zhao and D. Zhang, 2004. Single-phaseto-ground fault feeder detection based on transient current and wavelet packet. Proceedings of the 2004 International Conference on Power System Technology PowerCon Vol. 1, November 21-24, 2004, IEEE, Singapore, Singapore, pp: 936-940.

Bin Sulaiman, M., A.H. Tawafan and Z. Bin Ibrahim, 2013. Detection of high impedance fault using a probabilistic neural-network classfier. J. Theor. Appl. Inf. Technol., 53: 180-191.

Bin, L. and S. Hongchun, 2008. Research on extension method and detection of fault-line selection in resonant grounded systems. Proceedings of the 2008 Joint International Conference on Power System Technology and IEEE Power India, October 12-15, 2008, IEEE, New Delhi, India, ISBN:978-1-4244-1763-6, pp: 1-4.

Chaari, O. and M. Meunier, 1994. A recursive wavelet transform analysis of earth fault currents in Petersen-coil-protected power distribution networks. Proceedings of IEEE-SP International Symposium on Time-Frequency and Time-Scale Analysis, October 25-28, 1994, IEEE, Philadelphia, Pennsylvania, USA., pp: 162-165.

Chaari, O., M. Meunier and F. Brouaye, 1996. Wavelet: A new tool for the resonant grounded power distribution systems relaying. IEEE Trans. Power Delivery, 11: 1301-1308.

Chaari, O., P. Bastard and M. Meunier, 1995. Prony's method: An efficient tool for the analysis of earth fault currents in Petersen-coil-protected networks. IEEE. Trans. Power Delivery, 10: 1234-1241.

Chang, T., 2010. Impact of distributed generation on distribution feeder protection. Ph.D Thesis, University of Toronto-St. George Campus, Toronto, Canada.

Chen, X., X. Yin, X. Yin, J. Tang and M. Wen, 2015. A novel traveling wave based fault location scheme for power distribution grids with distributed generations. Proceedings of the 2015 IEEE International Conference on Power \& Energy Society General Meeting, July 26-30, 2015, IEEE, Denver, Colorado, USA., pp: 1-5.

Chunju, F., K.K. Li, W.L. Chan, Y. Weiyong and Z. Zhaoning, 2007. Application of wavelet fuzzy neural network in locating Single Line to Ground fault (SLG) in distribution lines. Intl. J. Electr. Power Energy Syst., 29: 497-503.

Cui, T., X. Dong, Z. Bo and A. Juszczyk, 2010. Hilbert-transform-based transient/intermittent earth fault detection in noneffectively grounded distribution systems. IEEE. Trans. Power Delivery, 26: 143-151. 
Dong, X. and S. Shi, 2008. Identifying single-phase-to-ground fault feeder in neutral noneffectively grounded distribution system using wavelet transform. IEEE. Trans. Power Delivery, 23: 1829-1837.

Dwivedi, A. and X. Yu, 2011. Fault location in radial distribution lines using travelling waves and network theory. Proceedings of the 2011 IEEE International Symposium on Industrial Electronics, June 27-30, 2011, IEEE, Gdansk, Poland, ISBN: 978-1-4244-9310-4, pp: 1051-1056.

Eldin, E.S.T., D.K. Ibrahim, E.M. Aboul-Zahab and S.M. Saleh, 2009. High impedance fault detection in EHV series compensated lines using the wavelet transform. Proceedings of the 2009 IEEE/PES International Conference on Power Systems and Exposition, March 15-18, 2009, IEEE, Seattle, Washington, USA., ISBN:978-1-4244-3810-5, pp: 1-10.

Elkalashy, N.I., A.M. Elhaffar, T.A. Kawady, N.G. Tarhuni and M. Lehtonen, 2010. Bayesian selectivity technique for earth fault protection in medium-voltage networks. IEEE. Trans. Power Delivery, 25: 2234-2245.

Elkalashy, N.I., M. Lehtonen, H.A. Darwish, M.A. Izzularab and I.T. Abdel-maksoud, 2007. Modeling and experimental verification of high impedance arcing fault in medium voltage networks. IEEE. Trans. Dielectr. Electr. Insul., 14: 375-383.

Fan, Y., 2017. Design of automatic detection model for single-phase earth fault in distribution network. J. Electron. Res. Appl., 1: 53-58.

Guo, M.F. and N.C. Yang, 2017. Features-clusteringbased earth fault detection using singular-value decomposition and fuzzy c-means in resonant grounding distribution systems. Intl. J. Electr. Power Energy Syst., 93: 97-108.

Guo, M.F., N.C. Yang and L.X. You, 2018. Wavelet-transform based early detection method for short-circuit faults in power distribution networks. Intl. J. Electr. Power Energy Syst., 99: 706-721.

Hanninen, S., 2001. Single phase earth faults in high impedance grounded networks: Characteristics, indication and location. Ph.D Thesis, VTT Technical Research Centre of Finland, Espoo, Finland.

Heidari, M., 2010. Decision support algorithms for power system and power electronic design. MSc Thesis, University of Manitoba, Winnipeg, Canada.

Hietalahti, A., 2010. Compatibility of traditional earth fault protection functions for long cable feeders in compensated networks. Master Thesis, University of Vaasa, Vaasa, Finland.
Jansson, D. and P. Wadstrom, 2014. Study of system earthing for $36 \mathrm{kV}$-collector grids for wind farms. MSc Thesis, Department of Energy and Environment, Chalmers University of Technology Gothenburg, Sweden.

Kasinathan, K., 2007. Power system fault detection and classification by wavelet transforms and adaptive resonance theory neural networks. Master's Thesis, University of Kentucky, Lexington, Kentucky.

Kawady, T.A., A.M. Taalab and M. El-Geziry, 2010. Impact of load variations on arcing fault detection in LV distribution networks. Proceedings of the 10th IET International Conference on Developments in Power System Protection (DPSP 2010) Managing the Change, March 29-April1, 2010, IEEE, Manchester, UK., pp: 1-5.

Kim, C.J., S.J. Lee and S.H. Kang, 2004. Evaluation of feeder monitoring parameters for incipient fault detection using laplace trend statistic. IEEE Trans. Ind. Appl., 40: 1718-1724.

Lai, T.M., W.C. Lo, W.M. To and K.H. Lam, 2012. RMS percent of wavelet transform for the detection of stochastic high impedance faults. Proceedings of the 2012 IEEE 15th International Conference on Harmonics and Quality of Power, June 17-20, 2012, IEEE, Hong Kong, China, ISBN:978-1-4673-1944-7, pp: 823-828.

Li, L., 2013. A fault line detection method based on wavelet packet analysis in distribution network. Adv. Mater. Res., 614: 1833-1840.

Liang, J., Z. Yun, F. Liu and Y. Liu, 2002. A method of fault line detection in distribution systems based on wavelets. Proceedings of the International Conference on Power System Technology, October 13-17, 2002, IEEE, Kunming, China, pp: 2635-2639.

Lim, P.K. and D.S. Dorr, 2000. Understanding and resolving voltage sag related problems for sensitive industrial customers. Proceedings of the 2000 IEEE International Conference on Power Engineering Society Winter Meeting (Cat. No. 00CH37077) Vol. 4, January 23-27, 2000, IEEE, Singapore, Singapore, pp: 2886-2890.

Lin, X., I. Kursan, J. Sun, Z. Li and R. Zheng et al., 2014. Novel faulty feeder identification scheme in the neutral ineffectively grounded distribution networks. Proceedings of the 12th IET International Conference on Developments in Power System Protection (DPSP 2014), March 31-April 3, 2014, IET, Copenhagen, Denmark, ISBN:978-1-84919-834-9, pp: 1-6.

Lin, X., J. Huang and S. Ke, 2010. Faulty feeder detection and fault self-extinguishing by adaptive Petersen coil control. IEEE. Trans. Power Delivery, 26: 1290-1291. 
Lin, X., S. Ke, Y. Gao, B. Wang and P. Liu, 2011. A selective single-phase-to-ground fault protection for neutral un-effectively grounded systems. Intl. J. Electr. Power Energy Syst., 33: 1012-1017.

Liu, P. and C. Huang, 2017. Detecting single-phase-to-ground fault event and identifying faulty feeder in neutral ineffectively grounded distribution system. IEEE. Trans. Power Delivery, 33: 2265-2273.

Lobos, T., J. Rezmer and H.J. Koglin, 2001. Analysis of power system transients using wavelets and Prony method. Proceedings of the 2001 IEEE International Conference on Porto Power Tech (Cat. No. 01EX502) Vol. 4, September 10-13, 2001, IEEE, Porto, Portugal, Portugal, pp: 1-4.

Longhua, M. and M. Qinghai, 2002. Ground-fault protection based on active component of zero-sequence current in resistance neutral grounded distribution systems. Proceedings of the 2002 IEEE Region 10th Conference on Computers, Communications, Control and Power Engineering (TENCOM' 02) Vol. 3, October 28-31, 2002, IEEE, Beijing, China, ISBN:0-7803-7490-8, pp: 1897-1900.

Loos, M., 2013. Single phase to ground fault detection and location in compensated network. Ph.D Thesis, Universite Libre de Bruxelles-Archives \& Bibliothsques, Brussels, Belgium.

Loos, M., S. Werben, M. Kereit and J.C. Maun, 2013. Fault direction method in compensated network using the zero sequence active energy signal. Proceedings of the 2013 International Conference on Eurocon, July 1-4, 2013, IEEE, Zagreb, Croatia, ISBN: 978-1-4673-2230-0, pp: 717-723.

Ma, J., X. Yan, B. Fan, C. Liu and J.S. Thorp, 2015. A novel line protection scheme for a single phase-toground fault based on voltage phase comparison. IEEE. Trans. Power Delivery, 31: 2018-2027.

Michalik, M., M. Lukowicz, W. Rebizant, L. Seung-Jae and K. Sang-Hee, 2007. New ANN-based algorithms for detecting HIFs in multigrounded MV networks. IEEE. Trans. Power Delivery, 23: 58-66.

Moldovanova, E.A., R.A. Vainshtein and V.V. Shestakova, 2016. Detection of the faulted network element using frequency spectrum features of zero-sequence current under transient earth faults in the network with neutral grounding through Peterson-coil. Proceedings of the 2016 3rd International Conference on Electrical, Electronics, Computer Engineering and their Applications (EECEA), April 21-23, 2016, IEEE, Beirut, Lebanon, pp: 93-97.

Momoh, J.A., L.G. Dias and D.N. Laird, 1997. An implementation of a hybrid intelligent tool for distribution system fault diagnosis. IEEE. Trans. Power Delivery, 12: 1035-1040.
Mora, J.J., G. Carrillo and L. Perez, 2006. Fault location in power distribution systems using ANFIS nets and current patterns. Proceedings of the 2006 IEEE/PES International Conference on Transmission \& Distribution Conference and Exposition: Latin America, August 15-18, 2006, IEEE, Caracas, Venezuela, pp: 1-6.

Nayebi, V., M. Gandomkar and M.J. Ramezani, 2012. New method for high impedance faults detection using total harmonic distortion properties and time variations of current waveform. Intl. J. Autom. Power Eng., 1: 165-173.

Nikolaidis, V.C., E. Papanikolaou and A.S. Safigianni, 2016. A communication-assisted overcurrent protection scheme for radial distribution systems with distributed generation. IEEE. Trans. Smart Grid, 7: $114-123$.

Perera, N., A.D. Rajapakse, D. Muthumuni and R. Jayasinghe, 2009. Development of an on-line transient classification system. Proceedings of the International Conference on Power Systems Transients (IPST2009), June 3-6, 2009, Kyoto, Japan, pp: 1-6.

Piesciorovsky, E.C. and N.N. Schulz, 2017. Fuse relay adaptive overcurrent protection scheme for microgrid with distributed generators. IET. Gener. Trans. Distrib., 11: 540-549.

Ravlic, S. and A. Marusic, 2015. Simulation models for various neutral earthing methods in medium voltage systems. Procedia Eng., 100: 1182-1191.

Robertson, D.C., O.I. Camps, J.S. Mayer and W.B. Gish, 1996. Wavelets and electromagnetic power system transients. IEEE. Trans. Power Delivery, 11: 1050-1058.

Sagastabeitia, K.J., I. Zamora, A.J. Mazon, Z. Aginako and G. Buigues, 2011. Phase asymmetry: A new parameter for detecting single-phase earth faults in compensated MV networks. IEEE. Trans. Power Delivery, 26: 2251-2258.

Sedighi, A.R., M.R. Haghifam and O.P. Malik, 2005. Soft computing applications in high impedance fault detection in distribution systems. Electr. Power Syst. Res., 76: 136-144.

Shao, Z., L. Wang and H. Zhang, 2016. A fault line selection method for small current grounding system based on big data. Proceedings of the 2016 IEEE PES Asia-Pacific Conference on Power and Energy Engineering (APPEEC), October 25-28, 2016, IEEE, Xi'an, China, ISBN:978-1-5090-5419-0, pp: 2470-2474.

Sheng, Y. and S.M. Rovnyak, 2004. Decision tree-based methodology for high impedance fault detection. IEEE. Trans. Power Delivery, 19: 533-536. 
Venkataraman, K., B. Kirby, H. Ha and P. Newman, 2014. Transient earth fault detection on compensated earthed system. Proceedings of the 12th IET International Conference on Developments in Power System Protection (DPSP 2014), March 31-April 3, 2014, IET, Copenhagen, Denmark, ISBN: 978-1-84919-834-9, pp: 1-7.

Vijayachandran, G. and B.K. Mathew, 2012. High impedance arcing fault detection in MV networks using discrete wavelet transform and artificial neural networks. Proceedings of the 2012 International Conference on Green Technologies (ICGT), December 18-20, 2012, IEEE, Trivandrum, India, ISBN:978-1-4673-2635-3, pp: 089-098.

Wai, D.C.T. and X. Yibin, 1998. A novel technique for high impedance fault identification. IEEE. Trans. Power Delivery, 13: 738-744.

Wang, H., X. Cai and L. Liu, 2015. PSCAD simulation study on the distribution network voltage transformer failure. Proceedings of the 3rd International Conference on Mechatronics, Robotics and Automation (ICMRA 2015), April 20-21, 2015, Atlantis Press, Amsterdam, Netherlands, ISBN:978-94-62520-76-9, pp: 1401-1408.

Wang, Y., J. Yuan, X. Zeng and Y. Huang, 2013. A survey on faulty line selection technology for single-phase-to-ground fault in China. Proceedings of the 2013 IEEE International Conference on Industry Applications Society Annual Meeting, October 6-11, 2013, IEEE, Lake Buena Vista, Florida, pp: 1-5.

Wang, Y., Y. Huang, X. Zeng, G. Wei and J. Zhou et al., 2016. Faulty feeder detection of single phase-earth fault using grey relation degree in resonant grounding system. IEEE. Trans. Power Delivery, 32: 55-61.

Wangyi, J., Z. Xiangjun, X. Yao and Q. Xiao'an, 2009. A novel optimal control method of grounding impedance for distribution system. Proceedings of the 2009 International Conference on Transmission \& Distribution Conference \& Exposition: Asia and Pacific, October 26-30, 2009, IEEE, Seoul, South Korea, pp: 1-4.

Xiaobin, W., X. Shihua, Z. Hui and Z. Wei, 2018. A single-phase grounding fault judgment method based on mutation current logic matrix. Proceedings of the International Conference on Electrical Engineering, Control and Robotics (EECR 2018) Vol. 160, April 09, 2018, EDP Sciences, Les Ulis, France, pp: 1-5.
Yan-wen, W., L. Fei and Z. Zhong-Xiang, 2011. Support vector machine for classification and its application to the small current grounding fault line detection in peterson-coil-grounding system. Proceedings of the 2011 4th International Conference on Intelligent Computation Technology and Automation Vol. 1, March 28-29, 2011, IEEE, Shenzhen, Guangdong, China, ISBN:978-1-61284-289-9, pp: 727-730.

Yeo, S.M., C.H. Kim, K.S. Hong, Y.B. Lim and R.K. Aggarwal et al., 2003. A novel algorithm for fault classification in transmission lines using a combined adaptive network and fuzzy inference system. Intl. J. Electr. Power Energy Syst., 25: 747-758.

Zeng, X., K. Yu, Y. Wang and Y. Xu, 2016. A novel single phase grounding fault protection scheme without threshold setting for neutral ineffectively earthed power systems. CSEE. J. Power Energy Syst., 2: 73-81.

Zeng, X., K.K. Li, W.L. Chan, S. Su and Y. Wang, 2008. Ground-fault feeder detection with fault-current and fault-resistance measurement in mine power systems. IEEE. Trans. Ind. Appl., 44: 424-429.

Zeng, X.D., M.F. Guo and D.Y. Chen, 2017. Machine-learning-based single-phase-to-ground fault detection in distribution systems. Proceedings of the 2017 IEEE International Conference on Energy Internet and Energy System Integration (EI2), November 26-28, 2017, IEEE, Beijing, China, ISBN:978-1-5386-1428-0, pp: 1-6.

Zhang, J., B. Xu, X. Cai and L.J. Zhu, 2011. The diagnostic method of earth fault based on the evolution of fault in distribution network. Proceedings of the 2011 International Conference on Advanced Power System Automation and Protection Vol. 1, October 16-20, 2011, IEEE, Beijing, China, ISBN:978-1-4244-9622-8, pp: 770-774.

Zhou, C.C., Q. Shu and X.Y. Han, 2017. A single-phase earth fault location scheme for distribution feeder on the basis of the difference of zero mode traveling waves. Intl. Trans. Electr. Energy Syst., 27: 1-9 